\title{
Effect of surgical wound fluids after intraoperative electron radiotherapy on the cancer stem cell phenotype in a panel of human breast cancer cell lines
}

\author{
KAROLINA ZALESKA ${ }^{1}$, WIKTORIA MARIA SUCHORSKA ${ }^{1}$, ANNA PRZYBYŁA ${ }^{2}$ and DAWID MURAWA ${ }^{3,4}$ \\ ${ }^{1}$ Radiobiology Laboratory, Department of Medical Physics, Greater Poland Cancer Centre, 61-866 Poznań; \\ ${ }^{2}$ Department of Medical Biotechnology, Poznań University of Medical Sciences, 61-701 Poznań; \\ ${ }^{3}$ First Department of Surgical Oncology and General Surgery, Greater Poland Cancer Centre, 61-866 Poznań; \\ ${ }^{4}$ Regional Specialist Hospital in Wroclaw, Research and Development Centre, 51-124 Wroclaw, Poland
}

Received December 20, 2015; Accepted June 27, 2016

DOI: $10.3892 / \mathrm{ol} .2016 .5167$

\begin{abstract}
The wound healing process after surgery alters the area surrounding the original tumor and around the scar, and the modified microenvironment is more favorable for tumor recurrence. Intraoperative radiotherapy (IORT) is one of the more novel strategies in breast cancer $(\mathrm{BC})$ treatment. Irradiation during surgery has effects on the tumor microenvironment, abrogating the proliferative cascade induced by surgical wound healing. The aim of the present study was to determine the effect of surgical wound fluids from IOERT treatment (RT-WF) compared with wound fluids from conservative-breast surgery only (WF) on the cancer stem cell phenotype in a panel of $\mathrm{BC}$ cell lines. Post-operative wound fluids were derived from patients with $\mathrm{BC}$ who underwent a tumor resection (quadrantectomy) plus intraoperative electron radiotherapy using a single dose of $\leq 10$ Gy on the tumor bed and surrounding tissues, or from those who underwent a tumor resection without IOERT. Cell lines were incubated with $10 \%$ wound fluids, and after 4 days, the cluster of differentiation (CD) $44^{+} / \mathrm{CD} 24^{-/ \text {low }}$ phenotype and aldehyde dehydrogenase 1 (ALDH1) activity were determined by flow cytometry. The two types of fluid each affected the $\mathrm{CD} 44^{+} / \mathrm{CD} 24^{-/ \text {low }}$ phenotype. The results varied markedly between each cell line, even for the same histological subtypes. RT-WF decreased
\end{abstract}

Correspondence to: Mrs. Karolina Zaleska, Radiobiology Laboratory, Department of Medical Physics, Greater Poland Cancer Centre, 15 Garbary Street, 61-866 Poznań, Poland

E-mail: zaleska.kar@gmail.com

Abbreviations: BCT, breast-conserving therapy; IORT, intraoperative radiotherapy; IOERT, intraoperative electron radiotherapy; WF, wound fluids from surgery only; RT-WF, intraoperative radiotherapy wound fluids

Key words: breast cancer, cancer stem cells, intraoperative radiotherapy, surgical wound fluids the $\mathrm{CD} 44^{+} / \mathrm{CD} 24^{-/ \text {low }}$ populations in the basal-like BT-549 and MDA-MB-468 cell lines, whereas in the luminal type MCF7 cell line, the two fluids inhibited these populations. The HER-OE subtypes harbored a minimal CD44+/CD24//low population, but the growth of SK-BR-3 was stimulated by the two post-operative fluids. WF exhibited a stronger effect on ALDH1 activity compared with RT-WF. The stimulatory effect was dependent on the histological subtype of the cell line and the strongest dependence was observed in luminal subtypes characterized by low dehydrogenase activity in the control group. The present results enable a better understanding of the mechanism of recurrence and metastases following BC surgery. With respect to histological phenotype, its effect on tumor progression, either local or systemic, strongly suggests the requirement for further research and clinical validation.

\section{Introduction}

Breast cancer (BC) is the most common cancer in women, and is a heterogeneous disease, which has complicated its treatment and study (1). Based on the expression of specific receptors, $\mathrm{BC}$ is clinically divided into estrogen receptor (ER)-positive BC (the most common and diverse group), progesterone receptor (PR)-positive $\mathrm{BC}$ and human epidermal growth factor receptor 2 (HER2; also known as ERBB2)-positive BC, or in the absence of the three receptors, triple-negative BC (TNBC) (2).

Breast-conserving therapy (BCT) includes a wide local excision followed by adjuvant radiotherapy to the whole breast, and frequently, an additional boost to the tumor bed, including intraoperative radiotherapy (IORT) as one of the more novel strategies (3-6). The rationale for local dose escalation originates in the fact that after BCT, up to $90 \%$ of (at least first) local recurrences in the breast occur in the same quadrant as the primary cancer $(7,8)$. The largest evidence for boost IORT preceding whole breast irradiation exists for intraoperative electron radiotherapy (IOERT) with single doses of $\sim 10 \mathrm{~Gy}$. In any risk constellation, local recurrence rates are among the lowest reported thus far, as well as those of long-term follow-up analyses (9). Apart from the mere dose augmentation effect and the high topographical precision in delivery, immediate 
irradiation during surgery has been hypothesized to exhibit an effect on the tumor microenvironment, abrogating the proliferative cascade induced by surgical wound healing (10-13). Published data have suggested that the wound healing process subsequent to surgery alters the area surrounding the original tumor and around the scar, and that the modified microenvironment is more favorable for the tumor to recur. Local recurrence after surgery is particularly common in tumors characterized by HER 2 overexpression (14). It has been shown that wound fluids contain growth factors inducing the proliferation of HER2-positive BCs (15). Radiotherapy is not the only treatment that affects cell survival, surgery also has an impact on the tumor microenvironment. Belletti et al demonstrated the stimulatory effect of post-surgical drainage fluids on BC cells in fluids harvested from a group of patients after IORT treatment and from patients after breast-conserving surgery. It was shown that wound fluids from conservative surgery (without IORT) could stimulate the proliferation, migration and invasion of the $\mathrm{BC}$ cell lines, while fluids collected after IORT demonstrated different properties (16).

It has been proposed thatcancercells displaying the stem-like phenotype play a critical role in local recurrence, invasion and metastasis, as well as in radio- and chemoresistance (17-21). Al-Hajj et al identified a population of cluster of differentiation (CD) $44^{+} / \mathrm{CD} 24^{-/ \text {low }}$ cells from human breast tumors, which are more tumorigenic than other cell populations (22). In vivo experiments have shown that $\mathrm{CD} 44^{+} / \mathrm{CD} 24^{- \text {llow }}$ cells were able to generate tumors in NOD/SCID mice. Although a statistically significant association between the clinical behavior and the frequency of these cell populations was not observed, tumors with distant metastases exhibited a higher fraction of the $\mathrm{CD} 44^{+} / \mathrm{CD} 24^{-/ \text {low }}$ phenotype (23).

The presence of high aldehyde dehydrogenase 1 (ALDH1) activity is also associated with stem cell properties, with resistance to chemotherapy and a worse prognosis (24-26). Previous studies found that ALDH is involved in intracellular retinoic acid production correlated with metastasis, tumor grade, and HER2 and Ki-67 status (26-28). Dysregulation of signal transducer and activator of transcription 3 (STAT3) is sufficient for neoplastic transformation, and a previous study showed that constitutively active forms are able to promote malignant transformation in fibroblasts and tumor formation in mice (29). It has also been demonstrated that $\mathrm{ALDH}^{+}$and $\mathrm{ALDH}^{+} / \mathrm{CD} 44^{+} / \mathrm{CD} 24^{-}$subpopulations of BC cells express higher levels of phosphorylated STAT3 (30). The pharmacological targeting on STAT3 can suppress $\mathrm{ALDH}^{+}$and $\mathrm{ALDH}^{+} / \mathrm{CD} 44^{+} / \mathrm{CD} 24-$ cells in vitro and in vivo.

The aim of the present study was to determine the effect of surgical wound fluids from IOERT treatment (RT-WF) compared with wound fluids from conservative-breast surgery only (WF) on the $\mathrm{CD} 44^{+} / \mathrm{CD} 24^{-/ \text {low }}$ phenotype and ALDH1 activity in a range of different $\mathrm{BC}$ cell lines. The results obtained will enable a better understanding of the mechanism of recurrence and metastasis following BC surgery.

\section{Materials and methods}

Surgical wound fluids. Post-operative wound fluids were collected from 44 female patients, who underwent surgery for BC in Greater Poland Cancer Centre in Poznań, Poland.
The mean age of the patients was 58 years and the age range was 38-76 years. Two groups were analyzed. In the first group, following resection of the tumor (quadrantectomy), the patients underwent IOERT with up to a dose of $10 \mathrm{~Gy}$ per tumor bed and surrounding tissues. In the second group, the patients did not receive IOERT. In the two groups, the patients left the ward on the second day after the surgery. The follow-up examination was scheduled for 7 days post-surgery in the Hospital Outpatient Clinic. The patients underwent ultrasonography and were assessed for the presence of fluid in the tumor bed. If fluid was found, it was collected for tests by means of percutaneous aspiration. Fluids collected from the intraoperative group were marked as RT-WF (22 samples), and fluids from the surgery alone group were marked as WF (22 samples). Fluids were centrifuged for $25 \mathrm{~min}$ at $1,100 \mathrm{x}$ g in $40^{\circ} \mathrm{C}$, sterile filtered and stored at $-80^{\circ} \mathrm{C}$. The present study was approved by the Bioethics Committee of Poznań University of Medical Sciences (Poznań, Poland).

Cell culture. A total of 8 human $\mathrm{BC}$ cell lines were used: MDA-MB-231 (ER/PR ; HER2/Neu'), MDA-MB-468 (ER/PR'; HER2/Neu'), BT-20 (ER/PR; HER2/Neu'), BT-549 (ER/PR'; HER2/Neu'), defined as TNBC, SK-BR-3 (ER/PR; HER2/Neu ${ }^{+}$, BT-474 (ER/PR ${ }^{+}$; HER2/Neu ${ }^{+}$, MCF7 (ER/PR ${ }^{+}$; HER2/Neu') and T47D (ER/PR ${ }^{+}$; HER2/Neu'). All cell lines were obtained from the American Type Culture Collection (ATCC; Manassas, VA, USA) and cultured according to the ATCC instructions in a humidified atmosphere with 5\% carbon dioxide at $37^{\circ} \mathrm{C}$. The $\mathrm{BC}$ cell lines were chosen due to their distinct molecular profiles $(31,32)$. At $24 \mathrm{~h}$ prior to the experiments, the cells were seeded in 6-cm Petri dishes and cultured in standard medium overnight. Next, culture medium was changed to fresh medium containing $10 \%$ RT-WF or $10 \%$ WF. The cells were incubated for 4 days. A total of 22 samples of RT-WF and WF, respectively, were analyzed. Control cells were cultured in standard medium under the same conditions.

Flow cytometry. After 4 days of incubation, the cells were washed twice with phosphate-buffered saline (PBS; Sigma-Aldrich, St. Louis, MO, USA), detached using Accutase (Thermo Fisher Scientific Inc., Waltham, MA, USA) and re-suspended in PBS supplemented with $1 \%$ bovine serum albumin (Thermo Fisher Scientific Inc.). Cell density was calculated using a Moxi $\mathrm{Z}$ automated cell counter (Orflo Technologies, Ketchum, ID, USA). In total, $1 \times 10^{6}$ cells were used for the analysis. Combinations of fluorochrome-conjugated mouse anti-human monoclonal antibodies CD44 (APC; dilution, 1:20; catalog no. 559942), CD24 (PE; dilution, 1:20; catalog no. 555428) and appropriate isotype controls were obtained from BD Biosciences (Franklin Lakes, NJ, USA). The cells were incubated with the antibodies at $4^{\circ} \mathrm{C}$ in the dark for $1 \mathrm{~h}$. The labeled cells were analyzed using FACS Aria (BD Biosciences).

Aldefluor assay. The ALDEFLUOR kit (Stemcell Technologies, Grenoble, France) was used according to the manufacturer's protocol. Briefly, the cells were washed twice with PBS (Sigma-Aldrich) and detached using Accutase (Thermo Fisher Scientific, Inc.). Detached cells were re-suspended in fresh medium and cell density was calculated using a Moxi Z automated cell counter (Orflo Technologies). 
A

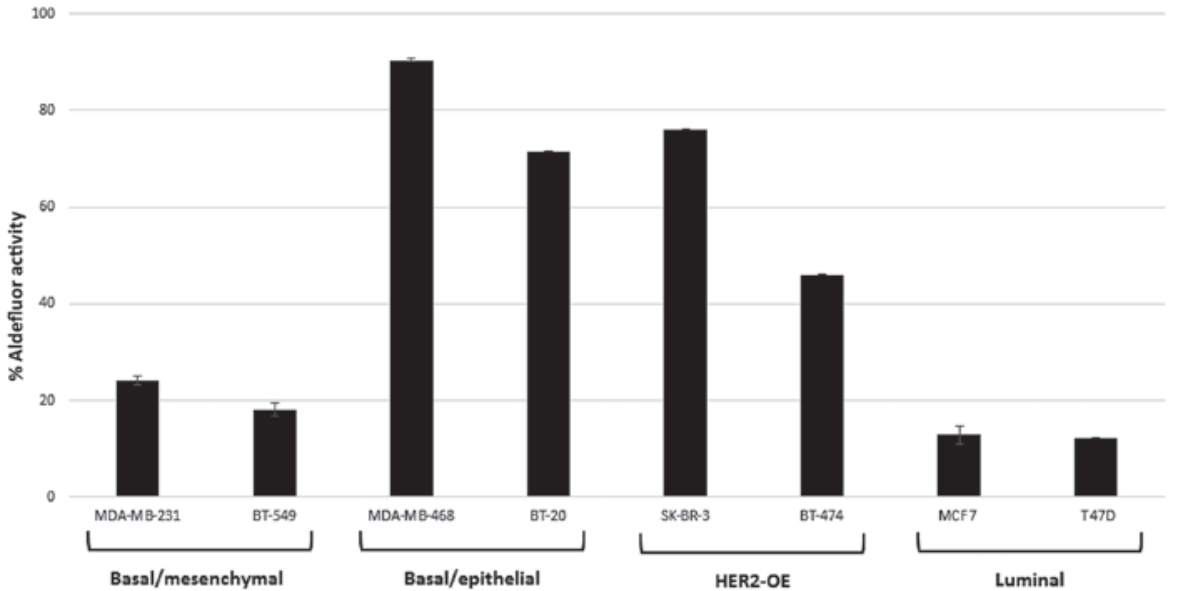

B

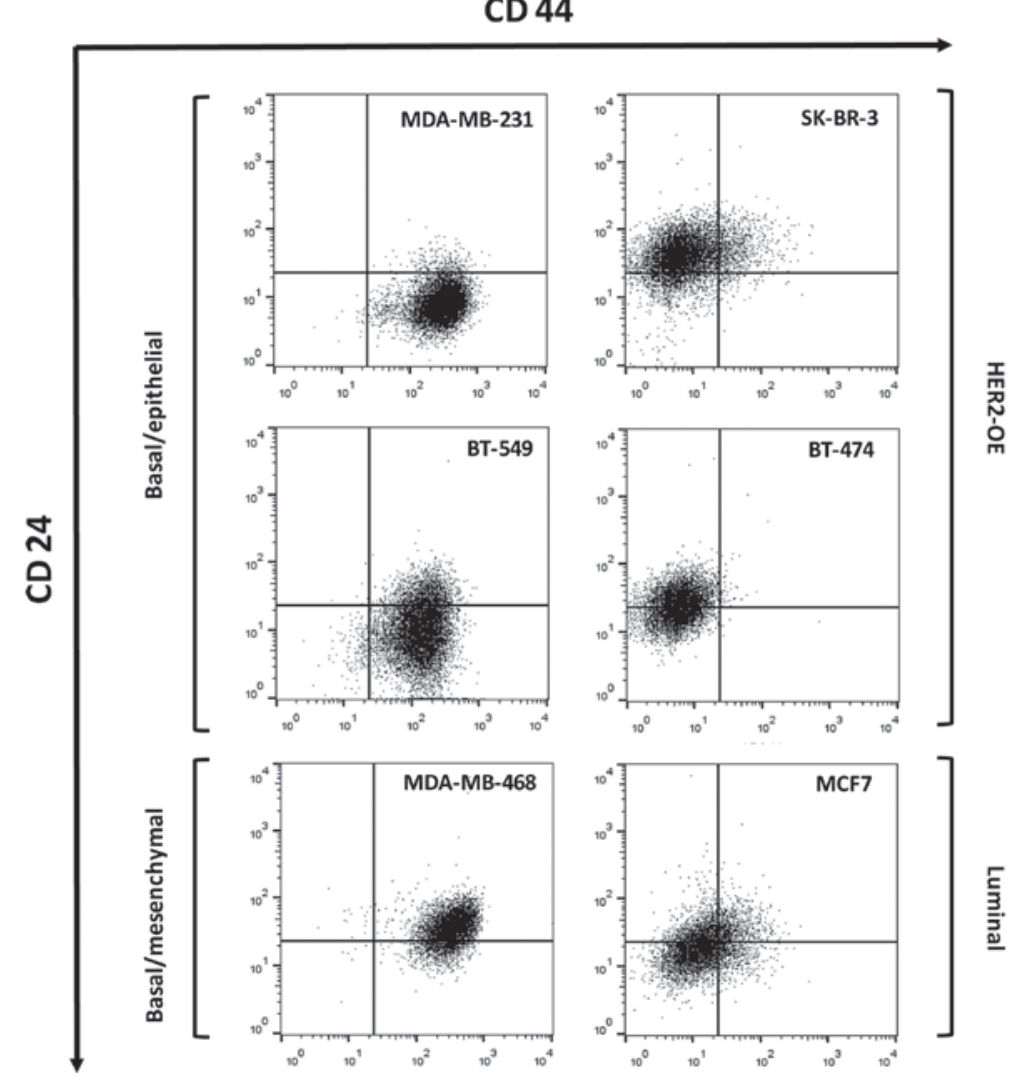

Figure 1. (A) The ALDH1-positive subpopulation varies between human BC cell lines according to the distinct molecular subtypes. Basal/epithelial and HER2 overexpressing protein cell lines exhibit strong ALDH1 activity. The mean of two independent experiments is plotted. (B) Subpopulations of CD44 ${ }^{+}$CD24 $4^{-/ 10 w}$ cells in human BC cell lines according to the distinct molecular subtypes. Basal-like cell lines are mainly constituted of cell populations with a high level of CD44 and a low level of CD24. The mean of three independent experiments is plotted. ALDH1, aldehyde dehydrogenase 1; HER2-OE, human epidermal growth factor receptor 2-overexpressing; $\mathrm{CD}$, cluster of differentiation.

In total, $2 \times 10^{5}$ cells were used for the analysis and incubated in ALDEFLUOR assay buffer containing ALDH substrate for $45 \mathrm{~min}$ at $37^{\circ} \mathrm{C}$. For each sample, negative controls were incubated under the same conditions with diethylaminobenzaldehyde. The labeled cells were analyzed using FACS Aria (BD Biosciences).

Statistical analysis. Data are expressed as the mean \pm standard deviation. Differences between two sample means were assessed using the Student's $t$-test. $\mathrm{P} \leq 0.05$ was considered to indicate a statistically significant difference. Statistical tests were performed using QuickCalcs, GraphPad online statistical calculator (GraphPad, La Jolla, CA, USA

\section{Results}

Cell selection. In total, 8 human $\mathrm{BC}$ cell lines were selected to be examined due to their histopathological and molecular profiles. Each cell line was characterized by different aldehyde dehydrogenase 1 (ALDH1) activity and the expression of a CD $44^{+} / \mathrm{CD} 24^{-/ \text {low }}$ subpopulation, even in cells of the same cancer subtypes (Fig. 1). The basal/epithelial (MDA-MB-468 


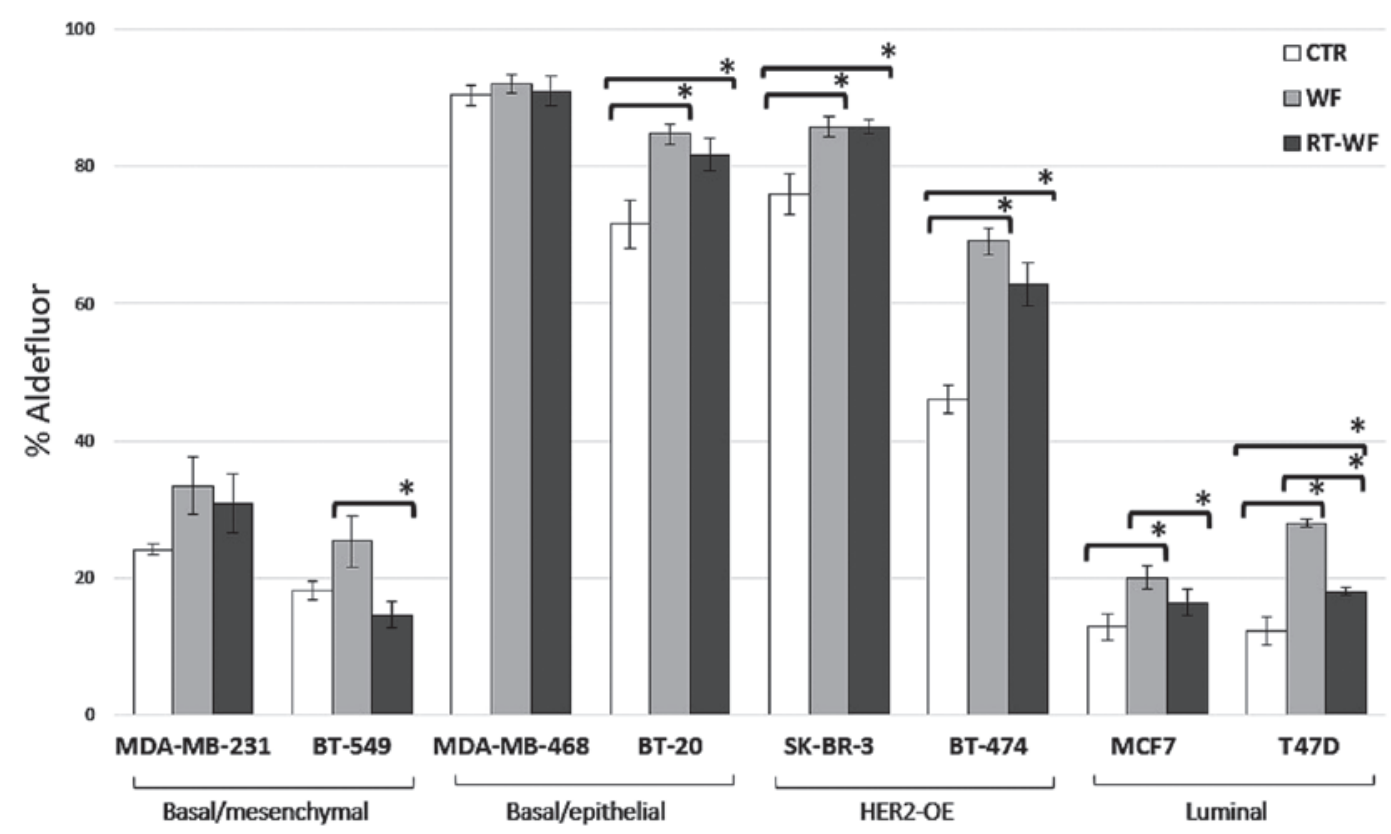

Figure 2. Wound fluids collected from patients who underwent surgery only (WF) had a stronger effect on ALDH1 activity compared with wound fluids harvested after the intraoperative electron radiotherapy procedure (RT-WF). The stimulatory effect was dependent on the histological subtypes of the cell lines. Columns represent the mean of 6-8 randomly selected WF and RT-WF. The control was harvested from medium supplemented with $10 \%$ fetal bovine serum only. Bars represent the standard deviation. Statistical analyses were conducted using Student's t-test. "P $\leq 0.05$. ALDH1, aldehyde dehydrogenase 1; CTR, control.

and BT-20) and HER2-overexpressing (HER2-OE; SK-BR-3 and BT-474) BC cell lines showed strong ALDH1 activity compared with the luminal (MCF7 and T47D) cell lines. Only the basal type (MDA-MB-231 and BT-549) expressed a high percentage of CD44-positive cells. All TNBC cell lines were characterized by a high proportion of $\mathrm{CD} 44^{+} / \mathrm{CD} 24^{-/ \text {low }}$ subpopulation cells compared with other cell lines.

Surgical wound fluids affect ALDH1 activity. ALDH1 activity was evaluated in the human BC cell lines using the ALDEFLUOR assay. Fig. 2 shows the percentage of the cell population with ALDH1 activity in cells incubated with $10 \%$ conditioned medium that were harvested after 4 days in standard conditions. In all cell lines, with the exception of the BT-549 cell line (WF vs. RT-WF, P=0.029), surgical wound fluids from both the conservative surgery and IORT procedure groups induced ALDH1 activity compared with the control group supplemented with 10\% FBS. The MDA-MB-468 and MDA-MB-231 cell lines demonstrated virtually no difference in ALDH1 activity between the control group and the treated cells (MDA-MB-468: CTR vs. WF, $P=0.207$; $C$ TR vs. RT-WF, $\mathrm{P}=0.671$; and $\mathrm{WF}$ vs. RT-WF, $\mathrm{P}=0.418$; MDA-MB231: CTR vs. WF, $\mathrm{P}=0.055$; $\mathrm{CTR}$ vs. RT-WF, $\mathrm{P}=0.141$; and WF vs. RT-WF, $\mathrm{P}=0.651$ ). Notably, WF demonstrated a stronger stimulating effect compared with RT-WF in the luminal subtypes of cell lines that were characterized by low ALDH1 activity in the control group (MCF-7: CTR vs. WF, $\mathrm{P}=0.006$; CTR vs. RT-WF, $\mathrm{P}=0.142$; and $\mathrm{WF}$ vs. $\mathrm{RT}-\mathrm{WF}, \mathrm{P}=0.045$ ).

Surgical wound fluids affect the CD44/CD24 phenotype. The surface expression of CD44 and CD24 was analyzed in the human BC cell lines using flow cytometry. Regarding specific molecular subtypes, the markers were differentially expressed.
Human BC cell lines after 4 days of incubation in $10 \%$ wound fluid conditioned medium demonstrated an altered proportion of $\mathrm{CD} 44^{+} / \mathrm{CD} 24^{- \text {-low }}$ cell populations (described as a BC stem cell marker). The results varied markedly between each cell line, even between the same histological subtypes (Fig. 3). The TNBC MDA-MB-231 cell line did not exhibit changes in the expression profile (CTR vs. WF, $\mathrm{P}=0.465$; CTR vs. RT-WF, $\mathrm{P}=0.262$; and WF vs. RT-WF, $\mathrm{P}=0.092$ ). Notably, other TNBC cell lines, such as BT-549 and MDA-MB-468, demonstrated the stimulatory effect of WF and the inhibitory effect of RT-WF compared with the control group (BT-549: CTR vs. WF, $\mathrm{P}=0.017$; CTR vs. RT-WF, $\mathrm{P}=0.021$; and WF vs. RT-WF, $\mathrm{P}=0.007$; MDA-MB-468: CTR vs. WF, $\mathrm{P}=0.001$; CTR vs. RT-WF, $\mathrm{P}=0.159$; and WF vs. RT-WF, $\mathrm{P}=0.017)$. These three cell lines were defined as exhibiting a basal-like phenotype and harbored more $\mathrm{CD} 44^{+} / \mathrm{CD} 24^{- \text {llow }}$ than non-TNBC cells. The SK-BR-3 cell line was constituted of low levels of the CD44-positive cell population, however, unexpectedly, the two types of post-operative fluids each had a significant stimulating effect on the $\mathrm{CD} 44^{+} / \mathrm{CD} 24^{-/ \text {low }}$ phenotype (CTR vs. WF, $\mathrm{P}=0.005$; $\mathrm{CTR}$ vs. $\mathrm{RT}-\mathrm{WF}, \mathrm{P}=0.001$; and WF vs. RT-WF, $\mathrm{P}=0.074)$. The luminal MCF7 cell line was mainly constituted by CD24-positive cells, nevertheless, the small population of $\mathrm{CD} 44^{+} / \mathrm{CD} 24^{- \text {/low }}$ cells decreased significantly due to incubation with WF and RT-WF (CTR vs. WF, $\mathrm{P}=0.018$; CTR vs. RT-WF, $\mathrm{P}=0.006$; and $\mathrm{WF}$ vs. RT-WF, $\mathrm{P}=0.680$ ). BT-474 did not contain a detectable CSC population in any variant.

The BT-20 cell line is mainly constituted by cells with the $\mathrm{CD} 44^{+} / \mathrm{CD}^{2} 4^{+}$non-invasive phenotype and is not altered by incubation with surgical wound fluid (data not shown). By contrast, the T47D cell line is shown to be enriched with a $\mathrm{CD} 44^{-} / \mathrm{CD} 24^{+}$cell population, which is considered to be 


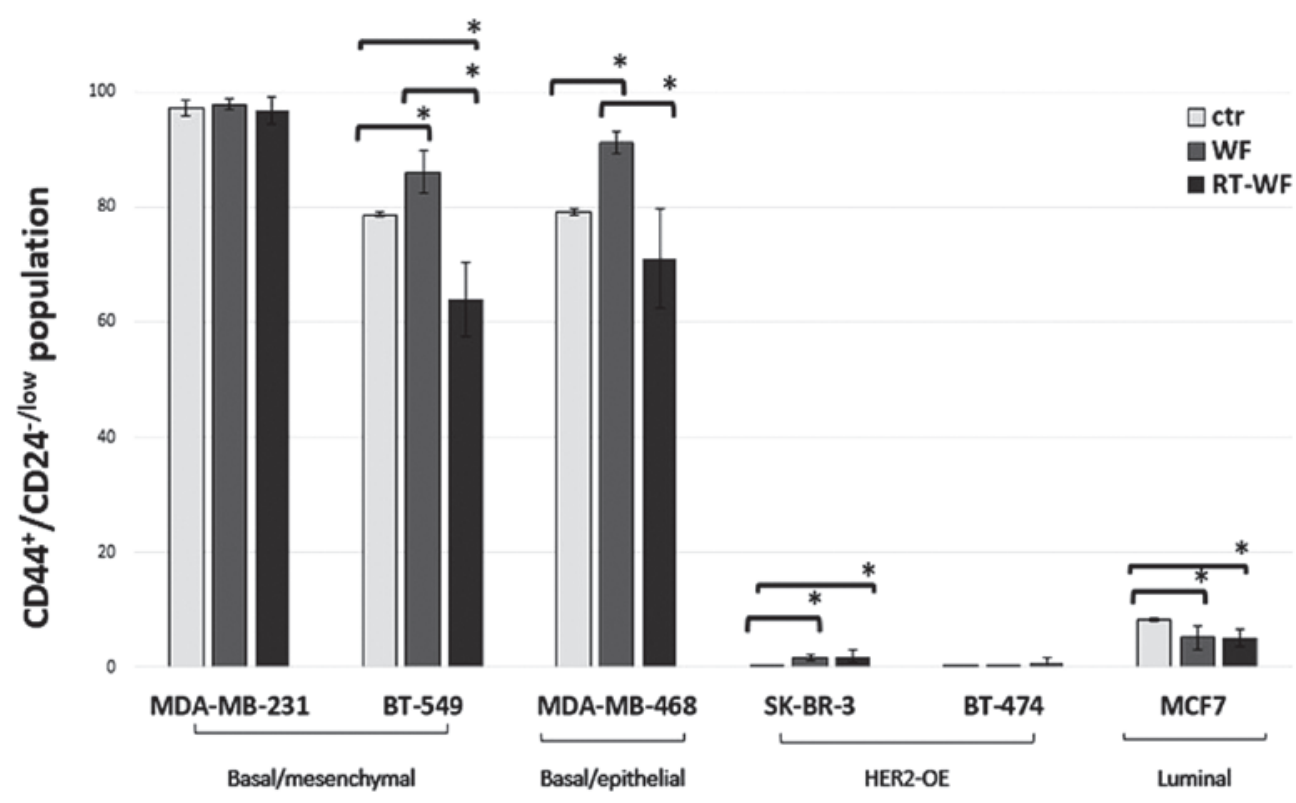

Figure 3. Changes in subpopulations defined by the $\mathrm{CD} 44^{+} / \mathrm{CD} 24^{-/ \text {low }}$ phenotype in a panel of 6 breast cancer cell lines harvested from surgical wound fluid $10 \%$ conditioned media depending on the molecular subtypes. RT-WF in basal-like BT-549 and MDA-MB-468 cell lines decreased the CD44 ${ }^{+} / \mathrm{CD} 24^{-/ l o w}$ populations, whereas in the luminal type MCF7 cell line, the two fluids each inhibited these populations. HER-OE subtypes harboured minimal CD44 $/$ CD24-low populations, but the SK-BR-3 cell line exhibited stimulated growth by use of each post-operative fluid. Columns represent the mean of 6-8 randomly selected WF and RT-WF. The control was harvested from medium supplemented with $10 \%$ fetal bovine serum only. Bars represent the standard deviation. Statistical analyses were conducted using Student's t-test. "P $\leq 0.05$. WF, wound fluids from surgery only; RT-WF, intraoperative radiotherapy wound fluids; HER2-OE, human epidermal growth factor receptor 2-overexpressing; $\mathrm{CD}$, cluster of differentiation; ctr, control.

unable to give rise to the invasive phenotype. The experiments were unable to identify how incubation with surgical wound fluid affected the CD44/CD24 phenotype in T47D, which had a high standard deviation and strong statistical insignificance (data not shown). Since these data are derived from different patients from the limited group, it was not possible to increase the research panel and try to redefine the associations between the cell line CD44/CD24 phenotype and the surgical wound fluids. For this reason, the BT549, BT-20 and T47D cell lines are not represented in certain cases, as the results were unreliable due to extreme results. These data indicate that each surgical wound fluid can affect the cell line biology individual.

Changes in all CD44 and CD24 expression variants. The impact of RT-WF and WF fluids on CD44 and CD24 (all expression variants) is presented in Fig. 4. In the basal-like cell lines, with the exception of the MDA-MB-231 cell line, RT-WF decreased the $\mathrm{CD} 44^{+} / \mathrm{CD} 24^{- \text {/low }}$ population while stimulating the $\mathrm{CD} 44^{+} / \mathrm{CD} 24^{+}$population, representing a non-invasive epithelial-like phenotype $\left(\mathrm{CD} 44^{+} / \mathrm{CD} 24^{- \text {-low }}\right.$ BT-549: CTR vs. WF, $\mathrm{P}=0.017$; CTR vs. $\mathrm{RT}-\mathrm{WF}, \mathrm{P}=0.021$; and WF vs RT-WF, $\mathrm{P}=0.007$; MDA-MB-468: CTR vs. WF, $\mathrm{P}=0.008$; CTR vs. RT-WF, $\mathrm{P}=0.159$; and $\mathrm{WF}$ vs. RT-WF, $\mathrm{P}=0.017$; $\mathrm{CD} 44^{+} / \mathrm{CD} 24^{+}$BT-549: $\mathrm{CTR}$ vs. $\mathrm{WF}, \mathrm{P}=0.175$; CTR vs. RT-WF, $\mathrm{P}=0.004$; and $\mathrm{WF}$ vs. $\mathrm{RT}-\mathrm{WF}, \mathrm{P}=0.003$; MDA-MB-468: CTR vs. WF, $\mathrm{P}=0.009$; CTR vs. RT-WF, $\mathrm{P}=0.085$; and $\mathrm{WF}$ vs. RT-WF, $\mathrm{P}=0.001$ ). HER2-OE-positive cell lines and luminal lines consist of the highest percentage of

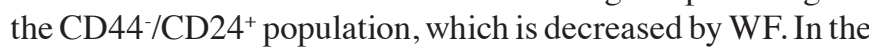
BT-474 cell lines, all surgical fluids stimulated a CD44-positive and CD24-postive population, whereas in the SK-BR-3 and MCF7 cell lines they stimulated a negative phenotype in these populations (BT-474 CD $44^{+} / \mathrm{CD} 24^{+}$: CTR vs. WF, $\mathrm{P}=0.003$; CTR vs. RT-WF, $\mathrm{P}=0.007$; and WF vs. RT-WF, $\mathrm{P}=0.707$; SK-BR-3 CD 44 $/ \mathrm{CD} 24:$ CTR vs. WF, $\mathrm{P}=0.042$; CTR vs. RT-WF, $\mathrm{P}=0.001$; and $\mathrm{WF}$ vs. $\mathrm{RT}-\mathrm{WF}, \mathrm{P}=0.008$; MCF-7 CD44/CD24: CTR vs. WF, P=0.005; CTR vs. RT-WF, $\mathrm{P}=0.001$, and $\mathrm{WF}$ vs. RT-WF, $\mathrm{P}=0.042$ ). Luminal and HER2-OE BC cell lines were constituted of cells with low levels of the CD44-positive population.

\section{Discussion}

The present study demonstrated that post-operative fluids harvested from patients who underwent breast-conserving surgery alone and from patients who received IOERT affect the stem cell phenotype in human BC cell lines. It is well established that surgery modifies the microenvironment, and that primary tumor removal may stimulate or accelerate metastatic spread. This phenomenon is known as tumor cell dormancy (33) and is likely to be important in treatment failure. Metastatic disease usually develops within 5 years of primary tumor treatment and more than half of patients succumb due to it (34). The wound healing process is a typical consequence of surgery, and it is currently believed that accompanying inflammation may contribute to aggressiveness and treatment resistance (35). The dormancy theory explains that molecular events associated with healing play a pivotal role as a 'start signal' to proliferation and the stimulation of angiogenesis (34). It has been shown that post-surgery wound fluids taken from $\mathrm{BC}$ patients can stimulate proliferation, metastasis and invasion $(15,16)$. The aforementioned results support the clinical observations and proves that surgery is a perturbing factor and a cause of treatment failure. Notably, the complete inhibition 

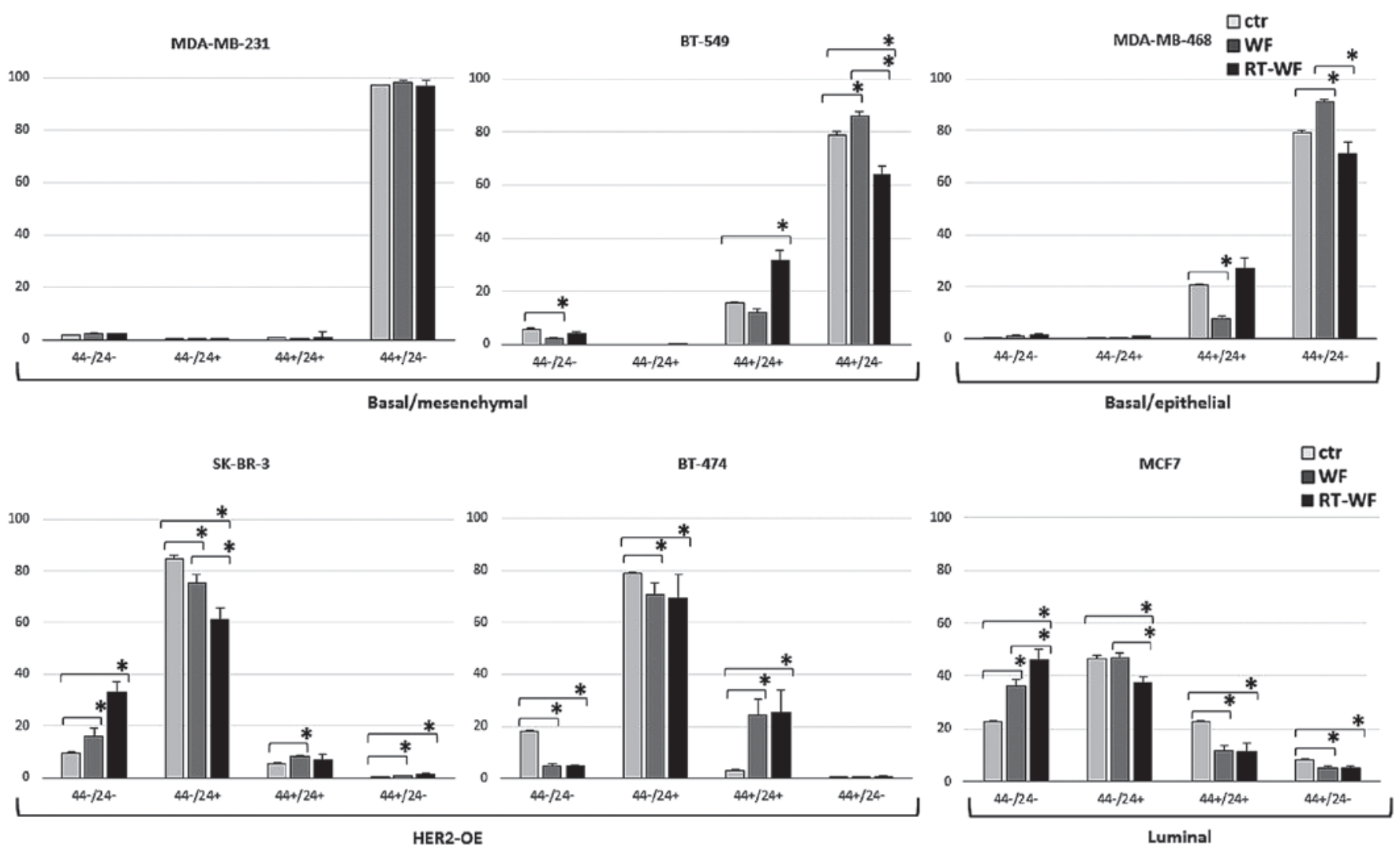

Figure 4. Effect of post-operative fluids on the CD44/CD24 phenotype in different human breast cancer cell lines. In the basal types, changes were slight between the $\mathrm{CD} 44^{+} / \mathrm{CD} 24^{- \text {/low }}$ and $\mathrm{CD} 44^{+} / \mathrm{CD} 24^{+}$phenotypes, whereas in the HER2-OE and luminal subtypes, changes were apparent in all CD44/CD24 subpopulations. Bars represent the standard deviation. Statistical analyses were conducted using Student's t-test. "P $\leq 0.05$. WF, wound fluids from surgery only; RT-WF, intraoperative radiotherapy wound fluids; HER2-OE, human epidermal growth factor receptor 2-overexpressing; CD, cluster of differentiation; ctr, control.

of proliferation and the delayed occurrence of metastases has been achieved in murine mammary studies using systemic treatment prior to or following surgery (36).

Inflammatory factors and changes in the microenvironment have been identified as modifying agents to tumor stem cells (37). CSCs exhibit the ability to self-renew, migrate and invade into surrounding tissues or distant organs, and are associated with radio- and chemoresistance. Due to these properties, CSCs have been proposed as attractive targets and a number of studies have been conducted to identify subpopulations of the cells responsible for treatment failure and tumor progression. Breast CSCs were first described by Al-Hajj et al (22) and identified as a CD44 $/ \mathrm{CD} 24^{-/ \mathrm{low}}$ high tumorigenic population. In vivo experiments showed that $\mathrm{CD} 44^{+} / \mathrm{CD} 24^{-/ \text {low }}$ cells were able to generate tumors in NOD/SCID mice. Numerous other studies confirmed these results in $\mathrm{BC}(23,38,39)$ and various other human tumor types (40). Generally, tumorigenicity and the stemness phenotype of these putative cells have been demonstrated by in vitro clonogenicity and in vivo tumorigenicity. A paradoxical phenomenon of tumor stem cells in BC exists, as there is no statistically significant association in the clinical behavior and the frequency of these cell populations $(23,36)$, however, tumors that develop distant metastases indeed exhibit a higher fraction of $\mathrm{CD} 44^{+} / \mathrm{CD} 24^{- \text {llow }}$ phenotype cells $(23,41)$.

In order to better understand the effect of surgical wound fluids on the putative stem cell population in BC, 8 different cell lines were examined in the present study. All models used in the study differed not only by the histological subtype, but also by the expression of the CD44 and CD24 subpopulation (Fig. 2). Basal-like cell lines expressed more $\mathrm{CD} 44^{+} / \mathrm{CD} 24^{-/ \text {low }}$ population cells as opposed to the luminal type, and according to literature data and clinical observations, these cells are associated with a worse prognosis (42). Belletti et al (16) observed changes in the proteomic profile between cells incubated in surgical fluids harvested from patients who underwent surgery alone and from those patients who received intraoperative radiotherapy. The fluids taken from the patients that received intraoperative radiotherapy showed reduced expression in several molecules linked to tumor growth and motility, including HGF and leptin, which can explain the different biological activities between the two groups of surgical fluids (16). It was therefore reasonable to hypothesize that surgical fluids can induce a putative stem cell population. Indeed, post-operative fluids affect the population, but those taken from patients treated using IORT (RT-WF) in the present study decreased the population of $\mathrm{CD} 44^{+} / \mathrm{CD} 24^{-/ \text {low }}$ cells in the basal and luminal groups. The strongest effect was observed in the BT-549 and MDA-MB-468 cell lines, whereas in HER-OE cell lines, identified as poorly equipped with $\mathrm{CD} 44^{+} / \mathrm{CD} 24^{-/ \text {low }}$, the result was the opposite. In the SK-BR-3 and BT-474 cell lines, the two surgical fluids were each able to stimulate the putative stem population. No effect was observed in the MDA-MB-231 cell line. A decrease in 
the $\mathrm{CD} 44^{+} / \mathrm{CD} 24^{-/ \text {low }}$ population was compensated for by an increase in the $\mathrm{CD} 44^{+} / \mathrm{CD} 24^{+}$population, which is considered to be not as tumorigenic (Fig. 4).

A study by Segatto et al largely explains how the surgery-wound response can promote a stem-like phenotype in BC cells via the STAT3 signaling pathway (37). A strong stimulation of the ability of mammosphere formation by wound fluid sera was observed in all examined cell lines. The presented results differed slightly. A dependence in the surgical fluid response according to the receptor expression in the cell line and the surgical fluid type used in the examination was observed (WF or RT-WF). Most likely, this effect is caused by the different times of fluid collection. In the present study, WF and RT-WF were collected at 7 days post-surgery by percutaneous aspiration, while in the aforementioned study (37), fluids were collected from drains at $24 \mathrm{~h}$ post-surgery. The difference in the time of collection is crucial in fluids, particularly in the panel of IORT-treated cell lines. Based on Belletti's results of the molecular analysis and the knowledge of surgery-induced inflammation (16), we believe that during the 1 week of the healing process, a pool of various molecules was accumulated that was responsible for the stronger effect on the putative stem phenotype.

While the subpopulation of cells with CD $44^{+} / \mathrm{CD} 24^{-/ \text {low }}$ expression has the highest invasiveness and metastatic potential in $\mathrm{BC}$, more and more studies indicate that the CD44-CD24+ population is a better prognostic marker in $\mathrm{BC}$ (43). The tissue microarray and histopathological analysis of patients' tumor samples indicates that CD $44^{-} / \mathrm{CD} 24^{+}$tumors have the worst prognosis in early invasive BC (43), and the tumor group exhibiting the $\mathrm{CD} 44^{+} / \mathrm{CD} 24^{-/ \text {low }}$ phenotype is considered a favorable prognostic subgroup in BC. Notably, in the present study, in the HER-OE cell lines and the luminal MCF7 cell line, this population was decreased by surgical fluids (Fig. 4). Meyer et al demonstrated that CD24 expression is under dynamic regulation in vitro and in vivo, and that the population of $\mathrm{CD} 44^{-} / \mathrm{CD} 24^{+}$cells can interconvert into CD $44^{+} / \mathrm{CD} 24^{- \text {/low }}$ cells and vice versa (44). This phenomenon can be explained as a consequence of loss of CD24 activity during tumor development or treatment.

ALDH activity is also associated with the putative stem cell phenotype. It was previously demonstrated that the expression of ALDH1 in breast tumors was a good predictor of a poor clinical outcome and this high activity was specific to the stemness phenotype (24). In turn, Zhong et al found that ALDH1 was not significantly associated with conventional clinical features such as tumor size or receptor expression, but was associated with breast tumor recurrence (45).

The present study assessed the impact of post-operative fluids on ALDH1 activity. A total of 8 cell lines were used with varied ALDH1 expression and activity that was comparable within the histological subtypes (Fig. 1A). to the best of our knowledge, the study presents the first examination of ALDH1 activity in BC affected by post-operative surgical fluids. Surgical fluids stimulated ALDH1 activity in all cell lines. However, RT-WF demonstrated a less stimulatory effect, which was most noticeable in the cell lines with a moderate ALDH1 level. Basal-like features are much more frequently associated with the incidence of metastasis than other subtypes. The present results showed that, as in the CD44/CD24 phenotype investigation, in this group of tumors, RT-WF inhibited the stimulation potential of fluids after surgery. Therefore, IORT may essentially contribute to treatment success.

The study did not observe that the examined putative breast CSC markers of a CD $44^{+} / \mathrm{CD} 24^{-/ \text {low }}$ phenotype and high ALDH1 activity result in the same response under post-operative surgical fluids, indicating that in vitro these markers do not correlate with the fluid response, and that behavior is an independent factor, subsidiary to the histopathological subtype. These results may be an explanation for the lower relapse rates in the TARGIT-A trial for patients treated with immediate IORT using $50-\mathrm{kV}$ orthovoltage (46).

The present study supports the hypothesis that surgery is a perturbing factor and explains how surgical intervention can impact the critical CSC behavior. To the best of our knowledge, this is the first study describing inhibitive mechanisms for IOERT. With respect to histological phenotype, the effect of the treatment on tumor progression, either local or systemic, strongly suggests a requirement for further research and clinical validation.

In summary, surgical wound fluids from the WF and RT-WF groups affected the putative stem cell phenotype, as determined by $\mathrm{CD} 44^{+} / \mathrm{CD} 24^{-/ \text {low }}$ and high ALDH1 activity. Following IOERT, a lower stimulation stem cell phenotype was observed in the RT-WF compared with the WF.

\section{Acknowledgements}

The present study was supported by the National Science Center, Kraków, Poland (grant no. UMO-2013/09/N/NZ4/02844). The authors would like to thank Professor Felix Sedlmayer from the University Clinic for Radiotherapy and Radio-Oncology (Salzburg, Austria) for providing editorial support and interactive communication.

\section{References}

1. Campbell LL and Polyak K: Breast tumor heterogeneity: Cancer stem cells or clonal evolution? Cell Cycle 6: 2332-2338, 2007.

2. Cancer Genome Atlas Network: Comprehensive molecular portraits of human breast tumours. Nature 490: 61-70, 2012.

3. Bitterman A, Kessner R, Goldman I, Shiloni E and Steiner M: Intraoperative radiotherapy for breast cancer. Isr Med Assoc J 14: 256-259, 2012.

4. Murawa P, Murawa D, Adamczyk B and Połom K: Breast cancer: Actual methods of treatment and future trends. Rep Pract Oncol Radiother 19: 165-172, 2014.

5. Williams NR, Pigott KH and Keshtgar MR: Intraoperative radiotherapy in the treatment of breast cancer: A review of the evidence. Int J Breast Cancer 2011: 375170, 2011.

6. Sedlmayer F, Reitsamer R, Fussl C, Ziegler I, Zehentmayr F, Deutschmann H, Kopp P and Fastner G: Boost IORT in breast cancer: Body of evidence. Int J Breast Cancer 2014: 472516, 2014.

7. Liberman L, Van Zee KJ, Dershaw DD, Morris EA, Abramson AF and Samli B: Mammographic features of local recurrence in women who have undergone breast-conserving therapy for ductal carcinoma in situ. AJR Am J Roentgenol 168: 489-493, 1997.

8. Fisher B, Dignam J, Wolmark N, Mamounas E, Costantino J, Poller W, Fisher ER, Wickerham DL, Deutsch M, Margolese R, et al: Lumpectomy and radiation therapy for the treatment of intraductal breast cancer: Findings from national surgical adjuvant breast and bowel project B-17. J Clin Oncol 16: $441-452,1998$.

9. Fastner G, Sedlmayer F, Merz F, Deutschmann H, Reitsamer R, Menzel C, Stierle C, Farmini A, Fischer T, Ciabattoni A, et al: IORT with electrons as boost strategy during breast conserving therapy in limited stage breast cancer: Long term results of an ISIORT pooled analysis. Radiother Oncol 108: 279-286, 2013. 
10. Demicheli R, Valagussa P and Bonadonna G: Does surgery modify growth kinetics of breast cancer micrometastases? Br J Cancer 85: 490-492, 2001.

11. Baum M, Demicheli R, Hurshesky W and Retsky M: Does surgery unfavorable perturb the 'natural history' of early breast cancer by accelerating the appearance of distant metastases? Eur J Cancer 41: 508-515, 2005.

12. Fisher B, Gunduz N, Coyle J, Rudock C and Saffer E: Presence of growth-stimulating factor in serum following primary tumor removal in mice. Cancer Res 49: 1996-2001, 1989.

13. Tsuchida Y, Sawada S, Yoshioka I, Ohashi Y, Matsuo M, Harimaya Y, Tsukada K and Saiki I: Increased surgical stress promotes tumor metastasis. Surgery 133: 547-555, 2003.

14. Ménard S, Balsari A, Casalini P, Tagliabue E, Campiglio M, Bufalino R and Cascinelli N: HER-2 positive breast carcinomas as a particular subset with peculiar clinical behaviors. Clin Canc Res 8: 520-525, 2002.

15. Tagliabue E, Agresti R, Carcangiu ML, Ghirelli C, Morelli D, Campiglio M, Martel M, Giovanazzi R, Greco M, Balsari A and Ménard S: Role of HER2 in wound-induced breast carcinoma proliferation. Lancet 362: 527-533, 2003.

16. Belletti B, Vaidya JS, D'Andrea S, Entschladen F, Roncadin M, Lovat F, Berton S, Perin T, Candiani E, Reccanello S, et al: Targeted intraoperative radiotherapy impairs the stimulation of breast cancer cell proliferation and invasion caused by surgical wounding. Clin Cancer Res 14: 1325-1332, 2008.

17. Dalerba P, Cho RW and Clarke MF: Cancer stem cells: Models and concepts. Annu Rev Med 58: 267-284, 2007.

18. Visvader JE and Lindeman GJ: Cancer stem cells in solid tumors: Accumulating evidence and unresolved questions. Nat Rev Cancer 8: 755-768, 2008.

19. Dean M, Fojo T and Bates S: Tumor stem cells and drug resistance. Nat Rev Cancer 5: 275-284, 2005.

20. Brunner TB, Kunz-Schughart LA, Grosse-Gehling P and Baumann M: Cancer stem cells as a predictive factor in radiotherapy. Semin Radiat Oncol 22: 151-174, 2012.

21. Bapat SA, Mali AM, Koppikar CB and Kurrey NK: Stem and progenitor-like cells contribute to the aggressive behavior of human epithelial ovarian cancer, Cancer Res 65: 3025-3029, 2005.

22. Al-Hajj M, Wicha MS, Benito-Hernandez A, Morrison SJ and Clarke MF: Prospective identification of tumorigenic breast cancer cells. Proc Natl Acad Sci USA 100: 3983-3988, 2003.

23. Abraham BK, Fritz P, McClellan M, Hauptvogel P, Athelogou M and Brauch H: Prevalence of $\mathrm{CD} 44^{+} / \mathrm{CD} 24^{-1 \text { low }}$ cells in breast cancer may not be associated with clinical outcome but may favor distant metastasis. Clin Cancer Res 11: 1154-1159, 2005.

24. Ginestier C, Hur MH, Charafe-Jauffret E, Monville F, Dutcher J, Brown M, Jacquemier J, Viens P, Kleer CG, Liu S, et al: ALDH is a marker of normal and malignant human mammary stem cells and a predictor of poor clinical outcome. Cell Stem Cell 1: 555-567, 2007.

25. Tanei T, Morimoto K, Shimazu K, Kim SJ, Tanji Y, Taguchi T, Tamaki Y and Noguchi S: Association of breast cancer stem cells identified by aldehyde dehydrogenase 1 expression with resistance to sequential paclitaxel and epirubicin-based chemotherapy for breast cancers. Clin Cancer Res 15: 4234-4241, 2009.

26. Croker AK, Goodale D, Chu J, Postenka C, Hedley BD, Hess DA and Allan AL: High aldehyde dehydrogenase and expression of cancer stem cell markers selects for breast cancer cells with enhanced malignant and metastatic ability. J Cell Mol Med 13: 2236-2252, 2009.

27. Marcato P, Dean CA, Giacomantonio CA and Lee PW: Aldehyde dehydrogenase: Its role as a cancer stem cell marker comes down to the specific isoform. Cell Cycle 10: 1378-1384, 2011.

28. Park SY, Lee HE, Li H, Shipitsin M, Gelman R and Polyak K: Heterogeneity of stem-cell related markers according to tumor subtype and histologic stage in breast cancer. Clin Cancer Res 16: 876-887, 2010.

29. Bromberg JF, Wrzeszczynska MH, Devgan G, Zhao Y, Pestell RG, Albanese C and Darnell JE Jr: STAT3 as an oncogene. Cell 98: 295-303, 1999
30. Lin L, Hutzen B, Lee HF, Peng Z, Wang W, Zhao C, Lin HJ, Sun D, Li PK, Li C, et al: Evaluation of STAT3 signaling in $\mathrm{ALDH}^{+}$and $\mathrm{ALDH}^{+} / \mathrm{CD} 44^{+} / \mathrm{CD} 24^{-}$subpopulations of breast cancer cells. PLoS One 8: e82821, 2013.

31. Holliday DL and Speirs V: Choosing the right cell line for breast cancer research. Breast Cancer Res 13: 215, 2011.

32. Neve RM, Chin K, Fridlyand J, Yeh J, Baehner FL, Fevr T, Clark L, Bayani N, Coppe JP, Tong F, et al: A collection of breast cancer cell lines for the study of functionally distinct cancer subtypes. Cancer Cell 10: 515-527, 2006.

33. Demicheli R, Retsky MW, Hrushesky WJ and Baum M: Tumor dormancy and surgery-driven interruption of dormancy in breast cancer: Learning from failures. Nat Clin Pract Oncol 4: 699-710, 2007.

34. Marches R, Scheuermann R and Uhr J: Cancer dormancy: From mice to man. Cell Cycle 5: 1772-1778, 2006.

35. Arnold KM, Opdenaker LM, Flynn D and Sims-Mourtada J: Wound healing and cancer stem cells: Inflammation as a driver of treatment resistance in breast cancer. Cancer Growth Metastasis 8: 1-13, 2015.

36. Fisher B, Gunduz N and Saffer EA: Influence of the interval between primary tumor removal and chemotherapy on kinetics and growth of metastases. Cancer Res 43: 1488-1492, 1983.

37. Segatto I, Berton S, Sonego M, Massarut S, Perin T, Piccoli E, Colombatti A, Vecchione A, Baldassarre G and Belletti B: Surgery-induced wound response promotes stem-like and tumor-initiating features of breast cancer cells, via STAT3 signaling. Oncotarget 5: 6267-6279, 2014.

38. Ma F, Li H, Wang H, Shi X, Fan Y, Ding X, Lin C, Zhan Q, Qian H and Xu B: Enriched CD44(+)/CD24(-) population drives the aggressive phenotypes presented in triple-negative breast cancer (TNBC). Cancer Lett 353: 153-159, 2014.

39. Camerlingo R, Ferraro GA, De Francesco F, Romano M, Nicoletti G, Di Bonito M, Rinaldo M, D'Andrea F and Pirozzi G: The role of $\mathrm{CD}_{4} 4^{+} / \mathrm{CD} 24^{-/ \text {low }}$ biomarker for screening, diagnosis and monitoring of breast cancer. Oncol Rep 31: 1127-1132, 2014

40. Shipitsin M, Campbell LL, Argani P, Weremowicz S, Bloushtain-Qimron N, Yao J, Nikolskaya T, Serebryiskaya T, Beroukhim R, Hu M, et al: Molecular definition of breast tumor heterogeneity. Cancer Cell 11: 259-273, 2007.

41. Sheridan C, Kishimoto H, Fuchs RK, Mehrotra S, Bhat-Nakshatri P, Turner CH, Goulet R Jr, Badve S and Nakshatri H: CD44+CD24- breast cancer cells exhibit enhanced invasive properties: An early step necessary for metastasis. Breast Cancer Res 8: R59, 2006.

42. Idowu MO, Kmieciak M, Dumur C, Burton RS, Grimes MM, Powers CN and Manjili MH: CD44(+)/CD24(-/low) cancer stem/progenitor cells are more abundant in triple-negative invasive breast carcinoma phenotype and are associated with poor outcome. Hum Pathol 43: 364-373, 2012.

43. Ahmed MA, Aleskandarany MA, Rakha EA, Moustafa RZ, Benhasouna A, Nolan C, Green AR, Ilyas M and Ellis IO: A CD 44/CD24+ $4^{+}$henotype is a poor prognostic marker in early invasive breast cancer. Breast Cancer Res Treat 133: 979-995, 2012.

44. Meyer MJ, Fleming JM, Ali MA, Pesesky MW, Ginsburg E and Vonderhaar BK: Dynamic regulation of CD24 and the invasive, CD44posCD24neg phenotype in breast cancer cell lines. Breast Cancer Res 11: R82, 2009.

45. Zhong Y, Lin Y, Shen S, Zhou Y, Mao F, Guan J and Sun Q: Expression of ALDH1 in breast invasive ductal carcinoma: An independent predictor of early tumor relapse. Cancer Cell Int 13: $60,2013$.

46. Vaidya JS, Wenz F, Max Bulsara M, Tobias JS, Joseph DJ, Keshtgar M, Flyger HL, Massarut S, Alvarado M, Saunders C, et al: Risk-adapted targeted intraoperative radiotherapy versus whole-breast radiotherapy for breast cancer: 5 -year results for local control and overall survival from the TARGIT-A randomised trial. Lancet 383: 603-613, 2014. 